\title{
Hanford Tank Waste Ion Exchange Swelling Task Technical and Quality Assurance Plan
}

by

D. J. McCabe

Westinghouse Savannah River Company

Savannah River Site

Aiken, South Carolina 29808

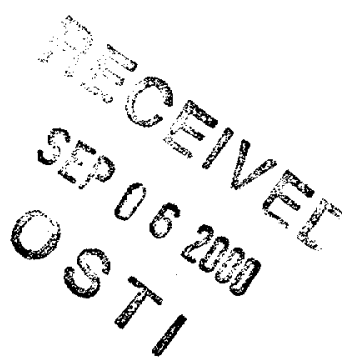

This paper was prepared in connection with work done under the above contract number with the U.S. Department of Energy. By acceptance of this paper, the publisher and/or recipient acknowledges the U.S. Government's right to retain a nonexclusive, royalty-free license in and to any copyright covering this paper, along with the right to reproduce and to authorize others to reproduce all or part of the copyrighted paper. 


\section{DISCLAIMER}

This report was prepared as an account of work sponsored by an agency of the United States Government. Neither the United States Government nor any agency thereof, nor any of their employees, makes any warranty, express or implied, or assumes any legal liability or responsibility for the accuracy, completeness, or usefulness of any information, apparatus, product or process disclosed, or represents that its use would not infringe privately owned rights. Reference herein to any specific commercial product, process or service by trade name, trademark, manufacturer, or otherwise does not necessarily constitute or imply its endorsement, recommendation, or favoring by the United States Government or any agency thereof. The views and opinions of authors expressed herein do not necessarily state or reflect those of the United States Government or any agency thereof.

This report has been reproduced directly from the best available copy.

Available for sale to the public, in paper, from: U.S. Department of Commerce, National Technical Information Service, 5285 Port Royal Road, Springfield, VA 22161, phone: (800) 553-6847

fax: (703) 605-6900

email: orders@ntis.fedworld.gov

online ordering: http://www.ntis.gov/ordering.htm

Available electronically at http://www.doe.gov/bridge

Available for a processing fee to U.S. Department of Energy and its contractors, in paper, from: U.S. Department of Energy, Office of Scientific and Technical Information, P.O. Box 62, Oak Ridge, TN 37831-0062, phone: (865) 576-8401

fax: (865) $576-5728$

email: reports@adonis.osti.gov 


\section{DISCLAIMER}

Portions of this document may be illegible in electronic image products. Images are produced from the best available original document. 


\section{Hanford Tank Waste Ion Exchange Swelling} Task Technical and Quality Assurance Plan (U)

October 19,1998

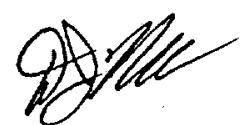

Daniel J. McCabe, 773-42A

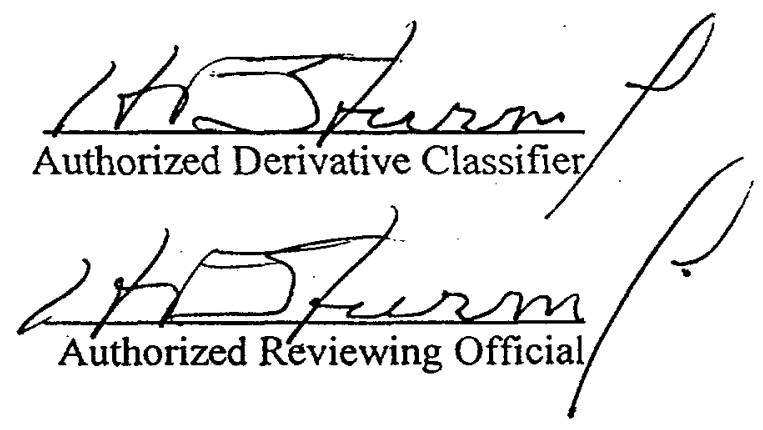

\section{DISCLAIMER NOTICE}

This report was prepared by Westinghouse Savannah River Company, Inc. (WSRC) on behalf of the U.S. Department of Energy (DOE), as an account of work sponsored by BNFL, Inc. Neither WSRC, DOE, the U.S. Government, or any person acting on their behalf makes any warranty, express or implied, or assumes any legal liability or responsibility for the accuracy, completeness, or usefulness of any information, apparatus, product, or process disclosed, or represents that its use would not infringe privately owned rights. Reference herein to any specific commercial product, process, or service by trade name, trademark, manufacturer, or otherwise, does not necessarily constitute or imply its endorsement, recommendation, or favoring by WSRC, DOE, or the U.S. Government. The views and opinions of authors expressed herein do not necessarily state or reflect those of WSRC, DOE, or the U.S. Government.

Savannạh River Technology Center

Westinghouse Savannah River Company

Aiken, SC 29808 


\subsection{Summary}

The swelling and density properties of ion exchange resins intended for pretreatment of Hanford High Level Waste will be examined. The resins are known to swell in highly alkaline salt solutions, and this behavior must be fully understood to develop resin pretreatment protocols. This plan describes the experiments needed to determine the swelling and density properties of the resins. This plan also describes the Quality Assurance protocols which will be followed. This task does not impact any RW0333P requirements. ${ }^{1}$

\subsection{Introduction}

\subsection{Definition}

The conceptualized process for treatment of Hanford High Level Waste decontaminates radioactive solutions by ion exchange removal of $\mathrm{Cs}^{137}$ with SuperLig@ 644 or 632 resins, Tc-99 removal with SuperLig® 639, and sulfate ion removal with SuperLig® 655. Other resins may also be used, as requested by BNFL, Inc.

The objective of this testing program is to define the resin pretreatment process for Hanford High Level Waste. This task will provide a basis for understanding resin swelling, which can lead to channeling and early breakthrough. The density of salt solution that leads to resin floating will also be determined to establish a limit for operation.

\subsection{Requesting Organization}

British Nuclear Fuels Inc. has requested this work through the Work For Others contract \#RNFE099802.

\subsection{Responsibilities}

Waste Processing Technology (WPT) and Chemical and Hydrogen Technology (CHT) will plan and conduct the ion exchange tests.

CHT will procure the needed equipment and chemicals to perform the experiments.

\subsection{Deliverables}

The test results will be provided to BNFL, Inc. in the form of a summary document. BNFL, Inc. will review and approve the document prior to finalization. 


\subsection{Task Acceptance Criteria}

The task activities will be reviewed and approved by BNFL, Inc. personnel. Results from the testing will be provided to BNFL, Inc. for input to the flow sheet design team.

\subsection{Task Activities}

\subsection{Equipment Description}

Simulant column

diameter: $2.5 \mathrm{~cm}$

resin volume: $40-50 \mathrm{~mL}$ (swelled)

gravity flow through column

\section{Column Apparatus}

The columns will be prepared and tested in duplicate. The resin will be retained in the column by means of quartz wool, but will be unobstructed on the top of the resin bed. All solutions will be introduced at the top of the column and allowed to drain through by gravity at 3 Column Volumes per hour. If the top surface of resin is disturbed by introduction of liquid, it will be re-leveled by gentle stirring and tapped . on the column exterior to promote re-settling. The liquid in the headspace will be minimized between solution cycles to reduce mixing. The columns will be equipped with graduations or a ruler to facilitate volume measurements.

The following resin characteristics will be recorded:

Resin volume

Buoyancy

Effluent color

Presence of fissures

Presence of bubbles

If the concentration of species are not achievable for the planned solution compositions, the maximum concentration will be used and the remaining tests at higher concentration will be eliminated.

During overnight storage, the resin column will be covered with Parafilm $®$ or similar material to reduce air absorption and evaporation.

The term "Column Volumes" (CV) will be defined as the resin volume measured after the first treatment with $0.25 \mathrm{M} \mathrm{NaOH}$. This volume will be used for all subsequent tests, regardless of the measured column volume. All tests will be done at ambient temperature. 


\subsection{Acid Cycling (SuperLig® 632, 644, 639, 655)}

1. Wet resin with deionized water for 24 hours in a poly bottle

2. Load the resin into the column and tap the column exterior to promote settling

3. Measure the wetted resin volume and observations

4. Pretreat the resin with $0.25 \mathrm{M} \mathrm{NaOH}$; allow solution to gravity drain at $150 \mathrm{~mL}$ per hour. Record resin volume and observations after every $150 \mathrm{~mL}$ are collected.

5. Continue pretreatment until two consecutive volume measurements are identical

6. Remove excess liquid from column headspace

7. Displace the $\mathrm{NaOH}$ solution with d.i. water until $3 \mathrm{CV}$ are collected

8. Record resin volume and observations after every $3 \mathrm{CV}$

9. Continue washing until two consecutive volume measurements are identical

10. Elute the resin with $0.5 \mathrm{M} \mathrm{HNO}_{3}$

11. Record resin volume and observations after collecting every $3 \mathrm{CV}$

12. Continue eluting until two consecutive volume measurements are identical

13. Remove excess liquid from column headspace

14. Displace $\mathrm{HNO}_{3}$ solution with $3 \mathrm{CV}$ of deionized water

15. Record resin volume and observations after $3 \mathrm{CV}$ have been collected

16. Pretreat the resin with $0.25 \mathrm{M} \mathrm{NaOH}$

17. Record resin volume and observations after every $3 \mathrm{CV}$ have been collected

18. Continue pretreatment until two consecutive volume measurements are identical

19. Remove excess liquid from column headspace

\section{3 pH Dependence (SuperLigß 632, 644)}

1. Use the resin samples previously pretreated with $0.25 \mathrm{M} \mathrm{NaOH}$

2. Treat the resin with $0.5 \mathrm{M} \mathrm{NaOH}$

3. Record resin volume and observations after collecting every $3 \mathrm{CV}$

4. Continue treating with this solution until two consecutive volume measurements are identical

5. Treat the resin with $3 \mathrm{CV}$ of $1.0 \mathrm{M} \mathrm{NaOH}$

6. Record resin volume and observations after collecting 1.5 and $3 \mathrm{CV}$

7. Repeat steps 5-6 for 3.0, 5.0, 7.0, and $8.0 \mathrm{M} \mathrm{NaOH}$. Stop testing if the resin floats. Continue to higher $\mathrm{NaOH}$ concentrations if the resin does not float (1 M increments).

8. Remove excess liquid from column headspace

9. Displace $\mathrm{NaOH}$ solution with deionized water for $3 \mathrm{CV}$

10. Record the resin volume and observations after $3 \mathrm{CV}$

11. Elute the resin with $0.5 \mathrm{M} \mathrm{HNO}_{3}$

12. Record resin volume and observations after every $1.5 \mathrm{CV}$ have been collected

13. Continue eluting until two consecutive volume measurements are identical

14. Remove excess liquid from column headspace

15. Displace $\mathrm{HNO}_{3}$ solution with deionized water for $3 \mathrm{CV}$

16. Record the resin volume and observations after $3 \mathrm{CV}$ 
17. Pretreat the resin with $0.25 \mathrm{M} \mathrm{NaOH}$ for $3 \mathrm{CV}$

18. Record resin volume and observations after every $1.5 \mathrm{CV}$ have been collected

19. Continue pretreatment until two consecutive volume measurements are identical

20. Remove excess liquid from column headspace

\subsection{Ionic Strength Dependence (SuperLig® 632, 644)}

1. Use the resin samples previously used in Section 4.3

2. Treat the resin with a solution containing $0.25 \mathrm{M} \mathrm{NaOH}$ and $0.25 \mathrm{M} \mathrm{NaNO}_{3}$ until 3 $\mathrm{CV}$ have been collected

3. Record resin volume and observations after $3 \mathrm{CV}$ have been collected

4. Continue pretreatment until two consecutive volume measurements are identical

5. Pretreat the resin with a solution containing $0.25 \mathrm{M} \mathrm{NaOH}$ and $0.75 \mathrm{M} \mathrm{NaNO}_{3}$ until 3 CV have been collected

6. Record resin volume and observations after $\underline{1.5}$ and $3 \mathrm{CV}$ have been collected

7. Repeat steps 5-6 for solutions containing:

\begin{tabular}{|l|l|}
\hline $\mathrm{NaOH}(\mathrm{M})$ & $\mathrm{NaNO} 3(\mathrm{M})$ \\
\hline 0.25 & 2.75 \\
\hline 0.25 & 4.75 \\
\hline 0.25 & 6.75 \\
\hline 0.25 & 7.75 \\
\hline
\end{tabular}

Terminate testing if the resin floats. Continue to higher $\mathrm{NaNO}_{3}$ concentrations if the resin does not float.

8. Displace the solution with $0.25 \mathrm{M} \mathrm{NaOH}$ until $3 \mathrm{CV}$ have been collected

9. Record the resin volume and observations.

10. Repeat steps 5-6 for solutions containing:

\begin{tabular}{|l|l|}
\hline $\mathrm{NaOH}(\mathrm{M})$ & $\mathrm{Na2SO4}(\mathrm{M})$ \\
\hline 0.25 & 0.375 \\
\hline 0.25 & 2.375 \\
\hline
\end{tabular}

11. Displace the solution with deionized water until $3 \mathrm{CV}$ have been collected

12. Record the resin volume and observations after 1.5 and $3 \mathrm{CV}$ have been collected

13. Elute the resin with $0.5 \mathrm{M} \mathrm{HNO}_{3}$

14. Record resin volume and observations after every 1.5 and $3 \mathrm{CV}$ have been collected

15. Continue eluting until two consecutive volume measurements are identical

16. Remove excess liquid from column headspace

17. Displace $\mathrm{HNO}_{3}$ solution with deionized water for $3 \mathrm{CV}$

18. Pretreat the resin with $0.25 \mathrm{M} \mathrm{NaOH}$ for $3 \mathrm{CV}$

19. Record resin volume and observations after every $\underline{1.5}$ and $3 \mathrm{CV}$ have been collected 
20. Continue pretreatment until two consecutive volume measurements are identical

21. Remove excess liquid from column headspace

\subsection{Buoyancy vs. Simulant Composition (SuperLig® 632, 644, 639, 655)}

1.Use the resin from Section 4.4

2.Prepare the following solution: Non-hazardous Envelope A (tk 241-AN-105) at 4.5 $5.0 \mathrm{M}$ total $\left[\mathrm{Na}^{+}\right]$

3.Add $\mathrm{NaNO} 3$ and $\mathrm{NaOH}$ to achieve the following concentrations:

\begin{tabular}{|l|l|l|l|l|}
\hline$\left[\mathrm{Na}^{+}\right](\mathrm{M})$ & Free $\left[\mathrm{OH}^{-}\right](\mathrm{M})$ & Free $\left[\mathrm{OH}^{-}\right](\mathrm{M})$ & Free $\left[\mathrm{OH}^{-}\right](\mathrm{M})$ & Free $\left[\mathrm{OH}^{-}\right](\mathrm{M})$ \\
\hline 5 & 0.75 & 1.0 & 1.5 & 2.0 \\
\hline 6 & 0.75 & 1.0 & 1.5 & 2.0 \\
\hline 7 & 0.75 & 1.0 & 1.5 & 2.0 \\
\hline 9 & 0.75 & 1.0 & 1.5 & 2.0 \\
\hline
\end{tabular}

4. Prepare the solutions at $0.75 \mathrm{M}$ and $2.0 \mathrm{M}$ free hydroxide, and perform steps 5-6. If a change in resin properties is observed, continue testing with the 1.0 and $1.5 \mathrm{M}$ free hydroxide solutions. If not, discontinue testing and proceed to step 7 .

5. Pass each of these solutions through the resin columns until $3 \mathrm{CV}$ have been collected.

6. Record the resin volume and observations after collecting 1.5 and $3 \mathrm{CV}$ of each solution

7. Displace simulant solution with deionized water until $3 \mathrm{CV}$ have been collected

8. Record the resin volume and observations

9. Elute the resin with $0.5 \mathrm{M} \mathrm{HNO}_{3}$

10. Record resin volume and observations after every $3 \mathrm{CV}$ have been collected

11. Continue eluting until two consecutive volume measurements are identical

12. Remove excess liquid from column headspace

13. Displace $\mathrm{HNO}_{3}$ solution with deionized water for $3 \mathrm{CV}$

14. Pretreat the resin with $0.25 \mathrm{M} \mathrm{NaOH}$ for $3 \mathrm{CV}$

15. Record resin volume and observations after every $3 \mathrm{CV}$ have been collected

16. Continue pretreatment until two consecutive volume measurements are identical

17. Displace the $\mathrm{NaOH}$ solution with $3 \mathrm{CV}$ of deionized water

18. Cover the column with Parafilm ${ }^{\circledR}$ to minimize air absorption or liquid evaporation during storage.

\subsection{Data Recording}

Sequential steps will be itemized in written instructions and recorded in a laboratory notebook. All activities will be conducted with approved procedures or written instructions, and all results will be recorded on data sheets entered in a laboratory notebook. Where applicable, analyses will be conducted by ADS and are governed by 
the ADS Quality Assurance program. All measurements will be conducted as routine analyses.

The following documents will become Quality Assurance Records:

- Technical Task and Quality Assurance Plan

- Results of any independent technical review .:

- Laboratory notebooks

- Supporting documentation as determined by the task leader.

- Procedure list and procedures required to provide supporting documentation

Quality Assurance Records shall be indexed and sent to BNFL, Inc. at project completion or placed in WSRC box storage if the customer does not request the records within 60 days of contract completion.

\subsection{Task Schedule}

Refer to "BNFL Part B schedule", S.T. Wach.

\subsection{Approvals}

\subsection{Design Check}

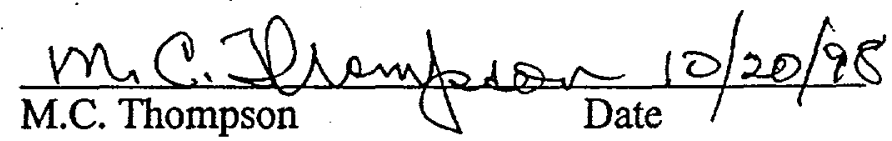

Chemical and Hydrogen Technology

\subsection{Approval}

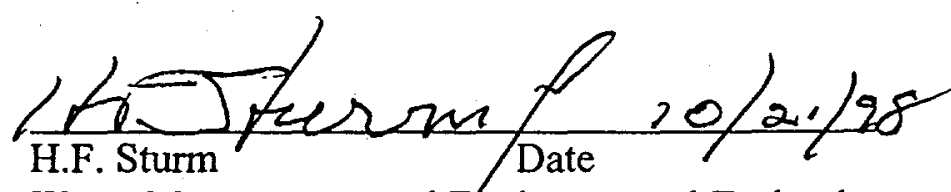

Waste Management and Environmental Technology

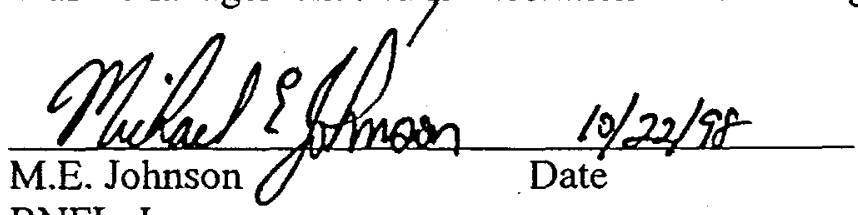

BNFL, Inc. 


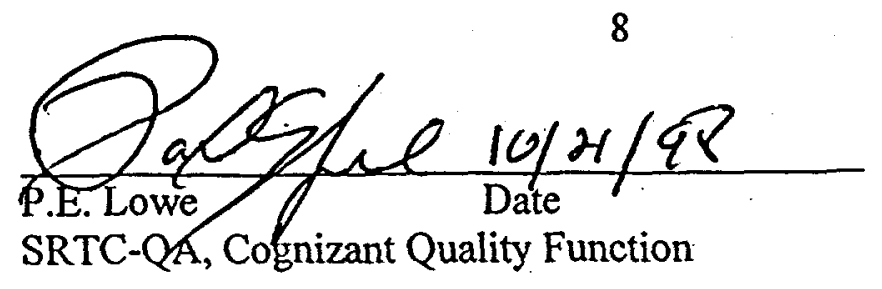

\subsection{References}

1. BNF-003-98-0008, Rev. 0, Savannah River Technology Center Quality Assurance Program Plan for British Nuclear Fuels Limited Work for Others Agreement (WFO98003)(U), P.E. Lowe, L.M. Nelson, to be published.

\subsection{Attachments}

\section{Attachment 1 - Task QA Plan Checklist}

\section{Distribution:}

S.T. Wach, 773-42A

M.E. Johnson, BNFL, Inc.

N.M. Hassan, 773-A

W.D. King, 773-42A

L.M. Nelson, 773-43A

BNFL Part B Document File, B. Skwarek, 773-41A 
TASK QA PLAN FOR THE TWRS PRIVATIZATION PROJECT

Document No.BNFL-003-98-0017

Revision No. 0

Listed below are the sections of the WSRC Quality Assurance Manual IQ. The contents of the 1Q Manual are responsive to the requirements of DOE Order 6700.6C, 10CFR830.120 and to the WSRC Quality Assurance Management Plan (WSRC-RP-92-225). WSRC IQ sections applicable to the work being performed for the TWRS Privatization Project should be indicated (mark Yes, No, or "AR"-as required). Also indicate procedures SRTC implements to control the work (including LI, 8.21, Supplemental QA Requirements for RW-0333P). This checklist identifies only procedures used to control work activities performed by SRTC for the TWRS Privatization Project. All identified procedures may not be applicable to each activity involved in the project.

\begin{tabular}{|c|c|c|c|}
\hline Yes & No & $\mathbf{A R}$ & \\
\hline & & & 1.1 ORGANIZATION \\
\hline $\mathbf{x}$ & & & 1Q, QAP 1-1, Organization \\
\hline \multirow[t]{3}{*}{$\bar{x}$} & & & LI, 1.02, SRTC Organization \\
\hline & & & \\
\hline & & & 1-2 STOP WORK \\
\hline \multirow[t]{3}{*}{$\bar{x}$} & & & 1Q, QAP 1-2, Stop Work \\
\hline & & & \\
\hline & & & 2-1 QUALITY ASSURANCE PROGRAM \\
\hline $\mathbf{x}$ & & & 1Q, QAP 2-1, Quality Assurance Program \\
\hline $\mathbf{x}$ & & & LI, 8.01, SRTC QA Program Implementation \\
\hline \multirow[t]{3}{*}{$\bar{x}$} & & & L1, 8.02, SRTC QA Program Clarifications, Attachment 8.2-1 \\
\hline & & & \\
\hline & & & 2-2 PERSONNEL TRAINING \& QUALIFICATION \\
\hline $\bar{x}$ & & & 1Q, QAP 2-2, Personnel Training \& Qualification \\
\hline $\bar{x}$ & & & L1, 5.01, SRTC Training, Orientation \& Employee Development \\
\hline $\bar{x}$ & & & L1, 1.32, Read \& Sign \\
\hline \multirow[t]{3}{*}{$\mathbf{x}$} & & & L1, 1.33, Employee \& Facility Access Orientation \\
\hline & & & \\
\hline & & & 2-3 CONTROL OF RESEARCH \& DEVELOPMENT ACTIVITIES \\
\hline $\bar{x}$ & & & 1Q, QAP 2-3, Control of Research \& Development Activities \\
\hline $\bar{x}$ & & & L1, 8.02, SRTC QA Program Clarifications, Attachment 8.2-3 \\
\hline \multirow[t]{9}{*}{$\bar{x}$} & & & L1, 7.10, Control of Technical Work \\
\hline & & & \\
\hline & & & 2-4 AUDITOR/LEAD AUDITOR QUALIFICATION \& CERTIFICATION \\
\hline & $\bar{x}$ & & 1Q, QAP 2-4, Auditor/Lead Auditor Qualification \& Certification \\
\hline & & & \\
\hline & & & $\begin{array}{l}\text { 2-5 QUALIFICATION \& CERTIFICATION OF INDEPENDENT } \\
\text { INSPECTION PERSONNEL }\end{array}$ \\
\hline & $\mathbf{x}$ & & 1Q, QAP 2-5, Qualification \& Certification of Independent Inspection Personnel \\
\hline & & & \\
\hline & & & 2-6 QA MANUAL REVISION \\
\hline \multirow[t]{7}{*}{$\bar{x}$} & & & 1Q, QAP 2-6, QA Manual Revisions \\
\hline & & & \\
\hline & & & $\begin{array}{l}\text { 2-7 QA PROGRAM REQUIREMENTS FOR ANALYTICAL } \\
\text { MEASUREMENT SYSTEMS }\end{array}$ \\
\hline & $x$ & & 1Q, QAP 2-7, QA Program Requirements for Analytical Measurement Systems \\
\hline & & & 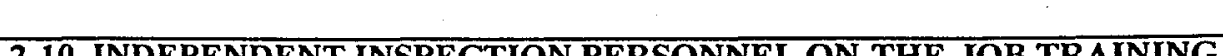 \\
\hline & $\therefore$ & $\therefore$ & 2-10 INDEPENDENT INSPECTION PERSONNEL ON-THE-JOB TRAINING \\
\hline & $\bar{x}$ & & 1Q, QAP 2-10, Independent Inspection Personnel - OTJ Training \\
\hline & & & \\
\hline
\end{tabular}




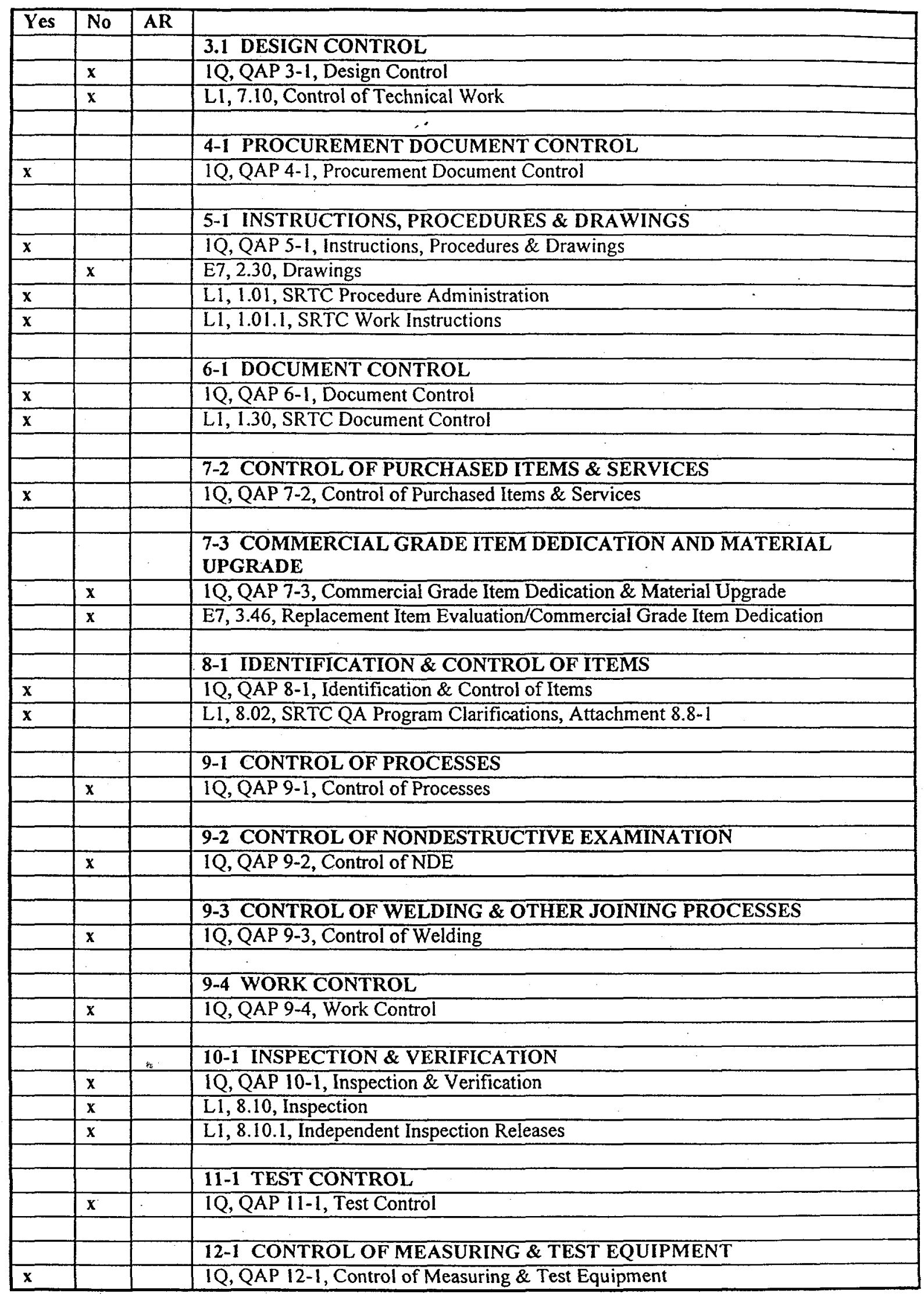




\begin{tabular}{|c|c|c|c|}
\hline Yes & No & $\mathbf{A R}$ & \\
\hline & & & 12-2 CONTROL OF INSTALLED PROCESS INSTRUMENTATION \\
\hline & $\mathbf{x}$ & & 1Q, QAP 12-2, Control of Installed Process Instrumentation \\
\hline & & & \\
\hline & & & $\begin{array}{l}\text { 12-3 CONTROL \& CALIBRATION OF RADIATION MONITORING } \\
\text { EQUIPMENT }\end{array}$ \\
\hline & $\bar{x}$ & & 1Q, QAP 12-3, Control of Radiation Monitoring Equipment \\
\hline & & & \\
\hline & & & 13-1 PACKAGING, HANDLING, SHIPPING \& STORAGE \\
\hline $\bar{x}$ & & & 1Q, QAP 13-1, Packaging, Handling, Shipping \& Storage \\
\hline $\mathbf{x}$ & & & L1, 8.02, SRTC QA Program Clarifications, Attachment 8.13-1 \\
\hline & & & \\
\hline & & & 14-1 INSPECTION, TEST \& OPERATING STATUS \\
\hline & $\bar{x}$ & & 1Q, QAP 14-1, Inspection, Test \& Operating Status \\
\hline & $x$ & & L1, 8.02, SRTC QA Program Clarifications, Attachment 8.14-1 \\
\hline & & & - \\
\hline $\bar{x}$ & & & 15-1 CONTROL OF NONCONFORMING ITEMS \\
\hline $\bar{x}$ & & & 1Q, QAP 15-1, Control of Nonconforming Items \\
\hline & & & Ll, 8.02, SRTC QA Program Clarifications, Attachment 8.15-1 \\
\hline & & & \\
\hline & & & 15-2 CONTROL OF NONCONFORMING ACTIVITIES \\
\hline $\bar{x}$ & & & 1Q, QAP 15-2, Control of Nonconforming Activities \\
\hline$x$ & & & LI, 8.02, SRTC QA Program Clarifications, Attachment 8.15-2 \\
\hline & & & \\
\hline & & & 16-1 CORRECTIVE ACTION SYSTEM \\
\hline $\mathbf{x}$ & & & 1Q, QAP 16-1, Corrective Action System \\
\hline & & & \\
\hline & & & 16-2 QUALITY ALERT \\
\hline $\bar{x}$ & & & 1Q, QAP 16-2, Quality Alert \\
\hline & & & \\
\hline & & & 17-1 QA RECORDS MANAGEMENT \\
\hline $\bar{x}$ & & & 1Q, QAP 17-1, QA Records Management \\
\hline $\mathbf{x}$ & & & L1, 8.02, SRTC QA Program Clarifications, Attachment 8.17-1 \\
\hline & & & $\therefore$ \\
\hline & & & 18-2 QUALITY ASSURANCE SURVEILLANCE \\
\hline $\mathbf{x}$ & & & 1Q, QAP 18-2, Quality Assurance Surveillance \\
\hline $\bar{x}$ & & & $\mathrm{LI}, 8.18 .1$, Surveillance \\
\hline & & & \\
\hline & & & 18-3 QUALITY ASSURANCE EXTERNAL AUDITS \\
\hline & $x$ & & 1Q, QAP 18-3, Quality Assurance External Audits \\
\hline & $\bar{x}$ & & L1, 8.18, SRTC Quality Assurance Audit Program \\
\hline & & & \\
\hline & & & 18-4 MANAGEMENT ASSESSMENTS \\
\hline $\bar{x}$ & & & 1Q, QAP 18-4, Management Assessments \\
\hline & & & \\
\hline & & & 18-6 Quality Assurance Internal Audits \\
\hline & $\bar{x}$ & & 1Q, QAP 18-6 \\
\hline & $\bar{x}$ & & L1, 8.18, SRTC Quality Assurance Audit Program \\
\hline & $=$ & $\because$ & \\
\hline & & & 19-2 QUALITY IMPROVEMENT \\
\hline & $\mathbf{x}$ & & 1Q, QAP 19-2, Quality Improvement \\
\hline & $\bar{x}$ & & L1, 8.02, SRTC QA Program Clarifications, Attachment 8.19-2 \\
\hline
\end{tabular}




\begin{tabular}{|c|c|c|c|}
\hline Yes & No & AR & \\
\hline & & & 20-1 SOFTWARE QUALITY ASSURANCE \\
\hline & $\bar{x}$ & & 1Q, QAP 20-1, Software Quality Assurance \\
\hline & $\mathbf{x}$ & & L1, 8.20, Software Management \& Quality Assurance \\
\hline & & & \\
\hline & & & 21-1 ENVIRONMENTAL QUALITY ASSURANCE \\
\hline & $\bar{x}$ & & 1Q, QAP 21-1, QA Requirements for the Collection \& Evaluation of Environ. Data \\
\hline & & & \\
\hline & & & $\begin{array}{l}\text { In addition to procedures noted above, if } \mathrm{RW}-0333 \mathrm{P} \text { requirements are invoked, } \\
\text { the following procedures may apply: }\end{array}$ \\
\hline & & & \\
\hline & & & Control of R\&D: \\
\hline & $\mathrm{x}$ & & L1, 8.21, Supplemental QA Requirements for RW-0333P \\
\hline & & & \\
\hline & & & Sample Control: \\
\hline & $\mathbf{x}$ & & LI, 3.07, Obtaining Analytical Services \\
\hline & $x$ & & L1, 2.21, Radioactive Sample Receiving, Labeling, \& Tracking \\
\hline & & & \\
\hline & & & Scientific Investigation: \\
\hline & $\mathbf{x}$ & & L1, 4.19, Laboratory Notebook Use \\
\hline
\end{tabular}




\section{R\&D Hazards Screening Checklist}

Listed below are characteristics of an experiment/project that may present hazards above normal risks to SRTC. Circle YES or NO for each item listed. For each "yes" answer you will be directed to a secondary hazard review or reviews that will direct completion of specific actions need to manage/mitigate the identified hazaṛ.

Project/Task: Hanford Tank Wapte Ion Exchange Swelling Task Technical and Quality Assurance Plan (U)

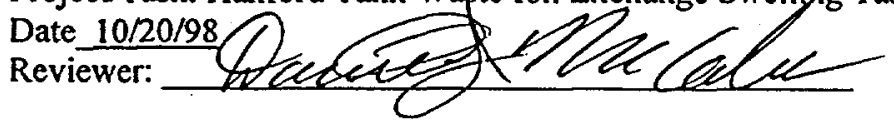

\section{ENERGIES}

A. Electricity (exposed energized parts $>50 \mathrm{~V}$ ).

See Figures $4 \& 11$.

B. Fissionable materials. Specify

See Figures 4, 5, 6, 7, 9, \& 11 .

C. High noise levels $(>85 \mathrm{dBA})$.

See Figures $4,8, \& 11$.

D. Microwave/radiofrequencies ( $30 \mathrm{KHz}-300 \mathrm{GHz}$ ), electric or magnetic fields. See Figures 4, 8, \& 11 .

E. Lasers (other than class 1 ).

See Figures 4, 8, \& 11 .

F. Moving equipment (exposed belts, chains, gears, pinch

rollers, pulleys, rotating shafts/blades, wheels, etc.)

See Figures 4 \& 11.

G. Radioactive materials. Specify: Radionuclides Physical Form See Figures 4, 5, 6, 7,9,\&11.

H. Static magnetic fields $>600$ Gauss. See Figures $4,8, \& 11$.

I. Sub-radiofrequency $(<30 \mathrm{KHz})$ electric and magnetic fields. See Figures $4,8, \& 11$.

J. Temperatures $\left(<32^{\circ} \mathrm{F}\right.$ or $\left.>150^{\circ} \mathrm{F}\right)$. Consider furnaces, ovens, dryers, boilers, steam systems, heaters, dewars, chillers, and release of compressed gases. See Figures $4,8,10, \& 11$.

K. Vacuum (external pressure $>15 \mathrm{PSI}$ ). See Figures 4, 8, \& 11.

L. Pressure (compressible materials $>30 \mathrm{PSI}$; or noncompressible materials $>150 \mathrm{PSI}$ ). See Figures $4,8, \& 11$.

M. Pressure vessels (> 15PSI and >6" ID; and/or contain toxic, corrosive, or nuclear materials). See Figures $4,8 \& 11$.

WORKSITE ENVIRONMENTAL CONDITIONS
A. Boating or work over water. See Figure 4, 8, \& 11
B. Cold or heat stress conditions. See Figure 4, 8, \& 11.
C. Confined spaces/trenches/or evacuations. See Figures $4,8, \& 11$.
D. Flammable atmospheres (>10\% LEL). $x$ See Figures $4,8,10, \& 11$.
E. Oxyger-deficient atmospheres $\left(<19.5 \% \mathrm{O}_{2}\right)$. $\quad x$ See Figures $4,8, \& 11$.
F. Toxic atmosphere (airborne contaminant concentrations expected to exceed $50 \%$ of the Threshold Limit Value). 
See Figures 4, 5, 8, \& 11.

G. Activity performed in a nuclear facility.

YES NO

See Figure 6.

H. Work with radioactive or contaminated material or entry

into controlled area. See Figures $6 \& 7$.

\section{HAZARDOUS MATERIALS}

A. Biological Agents.

See Figures 4, 5, 8, 9, \& 11 .

B. Carcinogens, mutagens, teratogens. Specify:

$x$

$\mathbf{X}$ See Figures 4, 5, 8, 9, \& 11.

C. Corrosives.

See Figures 4, 5, 8, 9, \& 11 .

D. Cryogenic gases/liquids.

See Figures $4,8, \& 11$.

E. Flammable/combustible gases, liquids, solids.

Specify: Amount:

F. Toxic Chemicals. Specify: Amount: $\leq 500 \mathrm{~g}$

See Figures $4,5,8,9,10, \& 11$.

G. Oxidizers. Specify: Amount: $\leq 500 \mathrm{~g}$

See Figures $4,5,8,9,10, \& 11$.

H. Hydrocarbons ( $>55$ gallons).

See Figures 4, 5, 8, 9, \& 11.

I. Any hazardous substance. Specify:

See Figures $4,5,8,9, \& 11$.

ENVIRONMENTAL COMPLIANCE

A. Release of regulated gas or particulate to the environment. $\mathrm{x}$ See Figure 9.

B. Release of regulated materials to a waste disposal system. $\mathrm{x}$ See Figure 9.

C. Waste disposal problems (including equipment). $\mathrm{x}$ . See Figure 9.

D. Creation of radioactive waste. See Figure 9. 